\title{
Enzymatic Coloration and Finishing of Wool with Laccase and \\ Polyethylenimine
}

\author{
Mengli Yuan ${ }^{1}$, Qiang Wang ${ }^{1, * *}$, Jinsong Shen ${ }^{2, *}$, Edward Smith $^{2}$, Rubing Bai ${ }^{1}$, Xuerong Fan $^{1}$ \\ ${ }^{1}$ Key Laboratory of Science and Technology of Eco-Textile, Ministry of Education, Jiangnan \\ University, Wuxi, 214122 Jiangsu, China \\ ${ }^{2}$ Textile Engineering and Materials (TEAM) Research Group, School of Design, De Montfort \\ University, Leicester, LE1 9BH, UK
}

\section{Correspondence:}

"Prof. Jinsong Shen (jshen@dmu.ac.uk), Textile Engineering and Materials (TEAM) Research Group, School of Design, De Montfort University, Leicester, LE1 9BH, UK.

***Prof. Qiang Wang (qiang_wang@163.com), Key Laboratory of Science and Technology of Eco-Textile, Ministry of Education, Jiangnan University, Wuxi, 214122 Jiangsu, China.

\begin{abstract}
Enzymes have been widely used in the textile wet processing. The precise reaction specificity of an enzyme has been utilised for specific or targeted textile finishing without causing undesirable fibre damage. Laccases are important enzymes for their application in textile processing due to their great versatility and capability of catalysing the oxidation of a broad range of substrates. The investigation of laccase-catalysed coloration towards either wool or polyethylenimine was carried out. It is understood that amino groups from wool and polyethylenimine are involved in the formation of polymeric colour during laccase catalysation of catechin and gallic acid. The colour depth and shrink-resistance of wool can be improved significantly by incorporating a multi-primary amine compound, such as polyethylenimine, and a crosslinking agent, such as glycerol diglycidyl ether, in the enzymatic coloration process of wool. This demonstrated the potential to achieve combined coloration and shrink-resistant finishing for wool fabrics.
\end{abstract}


Keywords: Laccase, Enzymatic coloration, Polyethylenimine, Wool

Abbreviations: PEI, Polyethylenimine; GDE, glycerol diglycidyl ether; owf, on weight of fabric

\section{Introduction}

Enzymes have been widely used in the textile wet processing, because enzymes can catalyse specific chemical reactions at comparatively mild conditions, resulting in energy saving. The precise reaction specificity of an enzyme can be utilised for specific or targeted textile finishing without causing undesirable fibre damage. The commonly used enzymes in textile processes are amylases, catalase, cellulase and laccase for various textile applications such as desizing, bioscouring, bleaching clean-up, biopolishing and bio-stone washing. ${ }^{1}$

Amongst the oxidase enzymes, there has been an increasing interest in the use of laccases for various applications. Laccases (EC 1.10.3.2) are multicopper oxidoreductases mainly secreted from bacteria and fungi. Laccases can catalyse the nonspecific oxidation of a wide range of substrates (see Fig. 1), leading to degradation of polymers and ring cleavage of aromatics. ${ }^{2-5}$ Due to their ability to catalyse the oxidation of phenolic compounds such as indigo dyes, laccases have been used in the washing process of denim jeans to achieve a colour fading, stone-washing effect without the use of pumice stone. ${ }^{6-9}$

\section{[Figure 1]}

Opposite to the enzymatic breakdown of phenolic compounds, laccases can also be used as a catalyst for oxidative coupling and polymerization of aromatic compounds. ${ }^{2,3}$ It has been reported that laccases are used in a "green" alternative method for the production of conventional phenolic resins, instead of the conventional use of toxic formaldehyde. ${ }^{12}$ The principal mechanism of laccase catalysation is an electron oxidation of phenolic compounds to form phenoxyl radicals using molecular oxygen as an electron acceptor. ${ }^{13,14}$ The phenoxyl radical may react with a second radical to form o-quinones, which are highly reactive electrophilic molecules, and can undergo further nucleophilic attack by other phenolic groups, 
amines, proteins and peptides in an enzymatic or a non-enzymatic pathway. ${ }^{15}$

Recently there is an increasing interest to develop enzymatic synthesis of colorants using laccase. Many colorants can be produced through laccase-catalysed oxidation of different phenolic compounds or related colourless precursors followed by further polymerisation leading to the formation of a polymeric chromogen structure. ${ }^{16-18}$ This could be an alternative to chemical synthesis of colorants for specific applications. However enzymatic synthesis of coloration is still in the early stage of research and their mechanisms are still uncertain. Research effort has also been made to develop enzymatic coloration of natural fibres, including cotton and wool, based on laccase-catalysed oxidation of phenolic compounds and their coupling reaction. ${ }^{19-23}$ After the oxidation of phenolic compounds to phenoxyl radicals, these reactive phenoxyl radicals could be nucleophilically attached to the surface of fibres, resulting in the formation of new bonds between phenols, polyphenolic compounds or polymerised colorants and fibres. Wool fibres have a substantial amount of nucleophilic amino groups available in the fibres. Therefore, there is potential for in situ dyeing of wool fibres by laccase with colourless precursors under milder conditions such as lower temperature and neutral $\mathrm{pH}$ than conventional wool dyeing. Tzanov et al. ${ }^{24}$ investigated the effect of processing parameters including dye precursor (2,5-diaminobenzenesulfonic acid) and dye modifiers (catechol and resorcinol) on the laccase-catalysed dyeing of wool. Bai et al. ${ }^{25}$ used catechol as a monomer to produce polymeric dyes via laccase-catalysed oxidation for dyeing wool in situ. The effect of different enzymatic processing methods with laccase on the dyeing of wool was discussed.

Because laccase can catalyse the oxidation of phenolic compounds followed by further polymerisation to produce polymeric colorants, the amino group of wool fibres might be involved in the polymerisation for colorants during the laccase catalysation, resulting in coloration of wool fibres. It would be of interest to investigate how the polymers containing amine groups are involved in the formation of polymeric colorants during the laccase catalysation. The present work selected a multi-primary amine compound, polyethylenimine (PEI) to investigate its effect on the laccase-catalysed oxidation and polymerization of 
phenolic compounds for generation of colour and in-situ wool dyeing. The involvement of polyethylenimine in the formation of a polymeric colorants during the laccase-catalysed coloration of wool was investigated. During the laccase-catalysed oxidation of phenolic compounds, nucleophilic amino groups from PEI and wool could be involved in the coupling reaction with the reactive phenoxyl radicals and integrated into the formation of polymeric colour.

A property of wool is its tendency to felt and shrink when washed, due to the configuration of cuticle scales on the surface of wool fibre. Wool shrink-resistance can be achieved by either removing the scales or smoothing the surface through polymer coating. Proteolytic enzymes have been suggested for incorporation in wool processing for improving shrink resistance. ${ }^{26}$ However, if not carefully controlled this enzymatic process can cause significant damage to the wool fibre due to the enzyme penetrating into and attacking the fibre core. ${ }^{27,28}$ It has been found that enzymatic pretreatment with protease in the scouring process can improve the scouring efficiency, resulting in the reduction of lipid content and an improvement in wool dyeability. ${ }^{29}$ Therefore, alkaline and protease pretreatments were carried out in the present work. A laccase based dyeing process incorporated with PEI polymer surface coating through a one-bath two step procedure was investigated for achieving wool coloration with improved shrink-resistance. There are no any previous studies in which enzymatic dyeing process is incorporated with shrink-resistance. There is a great potential for achieving the combination of wool coloration and shrink-resistant finishing with protein-based or polyamide-type shrink-resistant polymers in one treatment process.

\section{Materials and methods}

\subsection{Wool material}

The knitted 100\% wool fabric used, was supplied by Lokateks (Skofja Loka, Slovenia). It was a fine rib 1:1 knit with a dry weight of $220 \mathrm{~g} / \mathrm{m}^{2}$ constructed from a $40 \mathrm{Nm}$ single yarn with a mean fibre diameter of $21.9 \mu \mathrm{m}$. 


\subsection{Enzymes and chemicals}

The two enzymes used were an alkaline protease, Esperase 8.0L (EC 3.4.21.62) in liquid form and a laccase from Trametes versicolor (EC 1.10.3.2) in granulated form, both supplied by Novozymes A/S (Bagsvaerd, Denmark). Esperase $8.0 \mathrm{~L}$ is a subtilisin from Bacillus $s p$. and has an enzyme activity of $8.0 \mathrm{KNPU} / \mathrm{g}$. The laccase has an enzyme activity of $800 \mathrm{LAMU} / \mathrm{g}$. Ultravon PL, a synergetic preparation based on non-ionic surfactants, containing a fatty alcohol ethoxylate, was produced by Huntsman Textile Effects and purchased from Town End plc (Leeds, UK). Gallic acid (3,4,5-trihydroxybenzoic acid), catechin (trans-3,3',4',5,7-Pentahydroxyflavane hydrate), polyethylenimine (PEI) and the cross-linking agent, glycerol diglycidyl ether (GDE), were all purchased from Sigma-Aldrich (Dorset, UK). IEC reference detergent B and sodium perborate were purchased from SDC Enterprises Ltd (Bradford, UK). All other chemicals used were of specified laboratory reagent grade.

[Figure 2]

\subsection{Pretreatment of wool fabric by alkali scour or enzymatic scour}

Knitted wool fabric was pre-treated in an alkali scour solution containing $2 \mathrm{~g} / \mathrm{L}$ of the non-ionic surfactant Ultravon PL and $1.6 \mathrm{~g} / \mathrm{L}$ sodium carbonate at a liquor to goods ratio of 40:1 for 30 minutes at $60^{\circ} \mathrm{C}$ using a Roaches 8 pot Washtec wash wheel, with an agitation of $40 \mathrm{rpm}$.

Alternatively, knitted wool fabric was enzymatically pre-treated in $0.02 \mathrm{M}$ sodium tetraborate buffer at $\mathrm{pH} 8.5$ containing $2 \mu \mathrm{L} / \mathrm{gf}$ (per gram of fabric) Esperase and $2 \mathrm{~g} / \mathrm{L}$ of the non-ionic surfactant Ultravon PL at a liquor to goods ratio of $40: 1$ for 30 minutes at $60^{\circ} \mathrm{C}$ using a Roaches 8 pot Washtec wash wheel, with an agitation of $40 \mathrm{rpm}$. Then the wool fabric was heated in deionised water at $80^{\circ} \mathrm{C}$ for 10 minutes to deactivate Esperase.

After pre-treatment, all wool fabric samples were washed thoroughly with water, hydro-extracted at $2800 \mathrm{rpm}$ and then left to dry at the room temperature for two days. 
2.4 One-bath two step treatment for laccase-catalysed coloration and finishing of wool

The pretreated wool fabric was treated in $0.2 \mathrm{M}$ sodium acetate / acetic acid buffer set at pH 5 containing various concentrations of polyethylenimine (PEI) $(0 \%$ or $5 \%$ owf $)$, laccase $(0 \%$ or $5 \%$ owf) and gallic acid or catechin $(0 \%, 1 \%, 3 \%$, or $5 \%$ owf) at liquor to goods ratio of 40:1 for 4 hours at $50^{\circ} \mathrm{C}$ using a Roaches Washtec wash wheel. After treatment, the wool sample was washed thoroughly with water, hydro-extracted at $2800 \mathrm{rpm}$ to remove excess wetness, and then left to dry at the room temperature for two days.

Alternatively, the pretreated wool fabric were treated in $0.2 \mathrm{M}$ sodium acetate / acetic acid buffer set at $\mathrm{pH} 5$ containing $5 \%$ owf of laccase and $3 \%$ owf of gallic acid or catechin at liquor to goods ratio of $40: 1$ at $50^{\circ} \mathrm{C}$ for 3 hours. The treatment bath was then adjusted to $\mathrm{pH} 8$. Into the treatment bath 5\% owf of PEI and 15\% owf of the cross-linking agent glycerol diglycidyl ether (GDE) were added for a further 1 hour reaction. After the treatment was completed, the fabric samples were rinsed briefly with water and hydro-extracted at $2800 \mathrm{rpm}$ to remove excess wetness. The fabric was then cured at $140^{\circ} \mathrm{C}$ for $10 \mathrm{~min}$ in a fan assisted oven. Finally, the treated fabric was washed thoroughly with water, hydro-extracted at 2800 rpm, and then left to air-dry for two days.

\subsection{Weight loss and weight gain}

The weight loss of the wool fabric after pretreatment was expressed as a percentage, $\mathrm{W}_{\mathrm{L}}$ and was calculated using Equation 1:

$\% \mathrm{~W}_{\mathrm{L}}=100 \times\left(\mathrm{W}_{1}-\mathrm{W}_{2}\right) / \mathrm{W}_{1}$

The weight gain of the wool fabric after laccase-catalysed coloration and finishing was expressed as a percentage, $\mathrm{W}_{\mathrm{G}}$ and was calculated using Equation 2:

$\% \mathrm{~W}_{\mathrm{G}}=100 \times\left(\mathrm{W}_{3}-\mathrm{W}_{2}\right) / \mathrm{W}_{2}$

where $\mathrm{W}_{1}$ is the weight of conditioned wool fabric prior to pretreatment and $\mathrm{W}_{2}$ is the weight of conditioned wool fabric after pretreatment. $\mathrm{W}_{3}$ is the weight of conditioned wool fabric after laccase-catalysed coloration and finishing. 


\subsection{Shrinkage}

The enzyme treated knitted wool fabric was tested for relaxation and felting shrinkage due to washing, according to the Woolmark Test Method TM31: Washing of Wool Textile Products. The samples were subjected to a 7A wash cycle for relaxation shrinkage and 5A wash cycles up to 3 times for felting shrinkage using an Electrolux Wascator FOM 71washing machine. The temperature for each of the washing cycles was $40^{\circ} \mathrm{C}$. Polyester fabric make-weights were used to make up the washing load to $2 \mathrm{~kg}$ for each washing cycle. After each washing cycle the treated wool samples were dried flat at the room temperature for 48 hours and their dimensions were then measured. The area felting shrinkage was calculated as a percentage of the mean area dimensions of the fabric by measuring the length and width 3 times in each direction.

\subsection{Determination of colour strength}

Laccase-catalysed coloration of wool fabrics was undertaken in the presence or absence of precursors (catechin or gallic acid). A Datacolor SF600 Plus-CT reflectance spectrophotometer was used to determine the CIE $\mathrm{L}^{*} \mathrm{a} \mathrm{b}^{*}$ colour space values and colour strength $(\mathrm{K} / \mathrm{S})$ of the wool fabrics dyed through laccase catalysation. Each sample was measured four times. Values were measured using Color Tools QC software with illuminant/observer conditions of D65 $10^{\circ}$. Colour strength value $(\mathrm{K} / \mathrm{S})$ of the fabrics were calculated using the Kubelka-Munk equation (Equation 3)

$K / S=(1-R)^{2} /(2 R)$

where $\mathrm{K}$ is the coefficient of absorption; $\mathrm{S}$ is the coefficient of scattering; $\mathrm{R}$ is the reflectance value of the fabric at peak wavelength. The K/S value is directly proportional to the amount of colour present on the fabric and is usually calculated using the reflectance value at the wavelength of maximum absorption $\left(\lambda_{\max }\right)$ of the colour present on the fabric. This is expressed as $\mathrm{K} / \mathrm{S}$ at $\lambda_{\max }$. In order to access the overall colour strength of the dyed fabric over all visible wavelengths, $\mathrm{K} / \mathrm{S}$ at $10 \mathrm{~nm}$ intervals from $400 \mathrm{~nm}$ to $700 \mathrm{~nm}$ were added up to express as "Sum of $\mathrm{K} / \mathrm{S}$ ". 
The colour strength of residual dye bath or laccase-catalysed colour solution was evaluated. The dye bath solution was made up to the same fixed volume and absorbance measurements were taken at the all wavelength from $400 \mathrm{~nm}$ to $700 \mathrm{~nm}$ using a UV-2808S UV-Vis spectrophotometer (Unicosh, China).

\subsection{Scanning electron microscopy (SEM) of treated wool samples}

To determine the extent of fibre surface modification due to alkali scour or pretreatment with protease and changes due to laccase-catalysed coloration or crosslinking of PEI by GDE, micrographs were taken using SEM of the treated wool samples. Wool fabric samples were mounted on an aluminum stub using a double-sided adhesive carbon tab. For examination, the samples were coated with $15 \mathrm{~nm}$ of gold using a Quorum Q150RS sputter coater. Samples were examined using a Zeiss EVO LS15 microscope.

\section{Results and discussion}

3.1 Pretreament and laccase treatment of wool fabric in the absence of precursors

The pretreatments of wool fabrics in an alkaline scouring solution or a protease-contained scouring solution were carried out in order to remove any remaining grease and partially degrade the outermost lipid layer and cuticle cells by alkaline or enzymatic hydrolysis.

Alkaline scouring with detergent did not cause noticeable weight loss of the fabrics, as shown in Table 1. After further treatment with buffer, the fabric had shrunk up to $15.85 \%$ after 3 repeat 5A wash cycles. This indicates that the alkaline pretreatment might hydrolyse the lipid layer, but the cuticle scale configuration might remain undamaged, resulting in the felting shrinkage during washing. Alternative pretreatment with detergent in the presence of protease, Esperase, caused about $2.67 \%$ weight loss. This is because the protease in the pretreatment might catalyse the hydrolysis of protein compounds leading to the partial degradation of the cuticle scales of the wool and exposure of more amino and carboxylic acid groups on the surface of wool fibre. However, the pretreatment of wool fabric with protease did not produce the noticeable shrink-resistance. This was due to the small amount of protease used in the 
short time scouring process.

After pretreatment, the wool fabrics were subsequently treated with Laccase, PEI or the combination of laccase and PEI. It was confirmed that the treatment of wool with laccase and/or PEI at the optimum $\mathrm{pH} 5$ did not produce any colour on the wool fabric. Their maximum K/S values were no more than 0.71 which was almost the same as the control samples treated with buffer. Although laccase catalyses the oxidation in the processing, there was no effect on the shrink-resistance of wool to wash. However, the treatment of wool in the presence of PEI had some impact on the shrink-resistance, resulting in the reduction of area shrinkage from about $15 \%$ to $11 \%$ after three repeat $5 \mathrm{~A}$ wash cycles. This was due to the absorption of multi-primary amine compound polyethylenimine (PEI) on the surface of wool fibres through hydrogen bonding. The results suggested that the addition of PEI to the laccase treatment could confer shrink resistance performance to wool fabrics.

\subsection{Laccase-catalysed coloration of wool fabrics}

Enzymatic treatment of wool fabrics with laccase on its own did not produce colour on the fabrics. In order to achieve the enzymatic coloration of wool fabrics, two phenolic compounds, catechin and gallic acid, were introduced as precursors in the laccase treatment solution. After the wool fabrics were alkaline-scoured, the scoured fabrics were treated in a $0.2 \mathrm{M}$ acetate buffer containing laccase and either catechin or gallic acid in the presence or absence of PEI. Table 2 shows the effect of catechin and PEI on laccase-catalysed coloration of wool and the felting shrinkage due to washing. Catechin on its own did not cause noticeable staining or colour on the wool fabric during the treatment. When wool was treated with both laccase and catechin in the treatment bath at an optimum $\mathrm{pH} 5$ and temperature of $50^{\circ} \mathrm{C}$ for 4 hours, catechin was oxidised through laccase catalysation and polymerised to form a muted orange colour on wool. Its $\mathrm{K} / \mathrm{S}$ at $\lambda_{\max }$ was 11.28 and sum of $\mathrm{K} / \mathrm{S}$ over wavelength from $400 \mathrm{~nm}$ to $700 \mathrm{~nm}$ was 99.32 , as shown in Table 2 . It was suggested that laccase catalysed the oxidation of catechin into reactive quinone species which might polymerise themselves or react with amino groups from wool to form polymeric colour. When PEI was added in the laccase 
treatment bath with catechin, it was found that there was only light brown colour staining on wool fabric even when the concentration of catechin was increased to $5 \%$ on the weight of fabrics (owf). Its K/S at $\lambda_{\max }$ and sum of K/S were still only 3.66 and 23.64 respectively. These results suggest that laccase-precursor system and PEI together could not confer deep color to wool fabrics. However it was noticed that the residual solution had strong colour. This might be due to the competition between wool and PEI to react with laccase-oxidised catechin radicals to form colour. Soluble PEI might be more accessible than wool for reaction with oxidised catechin radicals to form colour compound during laccase catalysation. Therefore there was more intensity of colour remaining in the residual treatment bath.

Different colour could be generated by laccase catalysation with different phenolic precursors. Table 3 shows that laccase-catalysed coloration of wool with gallic acid. Gallic acid is a colourless compound. After wool was treated with laccase and gallic acid, a dark tan colour was formed on the wool fabric with a K/S at $\lambda_{\max }$ of 11.73 and sum of K/S of 130.43 over wavelength from $400 \mathrm{~nm}$ to $700 \mathrm{~nm}$. The same effect of addition of PEI into the laccase treatment in the presence of gallic acid on wool coloration was found. The colour on wool was significantly reduced. However, it was observed in both Tables 2 and 3 that the addition of PEI can reduce the felting shrinkage of wool fabrics due to its absorption on wool fibre surface.

Figs. 3 and 4 show colour measurement data of wool fabrics in term of K/S spectra over 400 $\mathrm{nm}$ to $700 \mathrm{~nm}$ after wool was enzymatically dyed with laccase in the presence or absence of PEI and either catechin or gallic acid. It was shown that the highest peaks of K/S responsible for the colour were at $400 \mathrm{~nm}$. The K/S of wool fabric dyed with laccase and phenolic compounds was much higher over whole visible spectrum than that dyed with laccase and phenolic compounds in the presence of PEI. Due to the colour formed by laccase over whole spectrum, it would be better to use sum of K/S from $400 \mathrm{~nm}$ to $700 \mathrm{~nm}$ for comparing the depth of colour.

From the results of Tables 2 and 3, wool fabrics were successfully dyed through laccase 
catalysation of phenolic compounds. Two different colour shades on wool fabrics were achieved by laccase catalysation of catechin and gallic acid respectively as shown in Table 4 with their CIE L* $a^{*} b^{*}$ colour space values and colour strength (K/S).

3.3 UV-Vis spectra of laccase-catalysed liquors without wool over visible wavelengths (400 $700 \mathrm{~nm})$

Wool fabrics were successfully dyed into deep colours by the treatment with laccase and catechin or gallic acid at $50^{\circ} \mathrm{C}$ for 4 hours. However, when PEI was introduced into laccase and precursor treatment liquor, wool fabrics were not able to pick up colour, although there was strong colour found in the residual bath. Therefore, the laccase-catalysed treatment baths without wool fabrics were investigated to find out whether PEI was involved in or inhibited the colour formation. The solutions of PEI with buffer, laccase with buffer or laccase with PEI were all clear and colourless after 4 hours incubation at $50^{\circ} \mathrm{C}$, and showed almost no absorbance in visible region, as shown in Figs. 5 and 6. The catechin solution in the absence of laccase was nearly colourless also. However incubation of laccase and catechin together either in the presence or absence of PEI produced deep colour, resulting in a high absorption in visible region of UV-vis spectra (Fig. 5). This is because that catechin was oxidised by laccase into intermediate reactive quinone radicals followed by polymerisation into polymeric colorants. The addition of PEI made the colour even stronger. This implied that PEI consisting of multi-amine groups was involved in the reaction with laccase-catalysed reactive quinone and subsequently to generate a stronger colour in the solution. The images of reacted solutions in Fig. 7 also show that the laccase-catechin-PEI solution appeared much stronger in colour than that of the laccase-catechin solution.

The UV-Vis spectra curves of the solutions of gallic acid oxidised by laccase in the presence and absence of PEI were very close (Fig. 6). From about $475 \mathrm{~nm}$ to $700 \mathrm{~nm}$, absorbance of solution of laccase-catalysed gallic acid with PEI was higher than that without PEI. However at $415 \mathrm{~nm}$ to $475 \mathrm{~nm}$, there is noticeable increase in the absorbance for the solution of laccase-catalysed gallic acid without PEI, resulting in the appearance of a shoulder on the 
curve. The change in shape of these curves might suggest that in the presence of PEI, laccase-oxidised gallic acid forms a new substance.

The results confirmed that PEI did not inhibit laccase catalysation of phenolic precursors to form colour at $\mathrm{pH} 5$. When laccase-catalysed phenolic precursors react with PEI, the PEI-precursor-polymerised colorants preferred to stay in aqueous solution rather than being uptaken onto the wool fibres, because PEI has good solubility in aqueous solution after being protonated at acidic solution. Therefore, the wool fibres need to compete with PEI for reaction with the active intermediate radicals of phenolic precursors being catalysed by laccase. Oxidation of gallic acid by laccase into intermediate reactive quinone radicals and further polymerisation into polymeric colorants is presented in Fig. 8. Their possible reactions of wool or PEI with the active intermediate radicals of gallic acid or its polymeric colourant catalysed by laccase are illustrated in Fig. 9. However, the wool fabric failed to take colour from the treated solution of laccase-precursors in the presence of PEI.

3.4 Laccase-catalysed coloration and finishing of wool fabrics through one-bath two step process

PEI can be involved in dye formation through laccase catalysation of phenolic compounds, producing a deeper colour. On the other hand, the treatment of wool with PEI could also improve wool shrink-resistance. However, wool could not be successfully dyed with laccase and either catechin or gallic acid in the presence of PEI. Therefore, a one-bath two step treatment for laccase-catalysed coloration and finishing of wool was proposed in order to improve the colour uptake and fixation of PEI-intergrated colorant. In the one-bath two step treatment, the pretreated wool fabrics were first treated with laccase and either catechin or gallic acid at $\mathrm{pH} 5$ and $50^{\circ} \mathrm{C}$ for 3 hours $\left(1^{\text {st }}\right.$ step). Then, the treatment bath containing laccase and precursor was adjusted to $\mathrm{pH} 8$ and 5\% owf of PEI with or without the cross-linking agent glycerol diglycidyl ether (GDE) was then added and treated for a further 1 hour at $50^{\circ} \mathrm{C}$ ( $2^{\text {nd }}$ Step), as illustrated in Fig. 10.

Table 5 shows the K/S value and felting shrinkage of wool fabrics processed through a 
one-bath two step treatment. It was found that the pretreated wool fabrics were dyed into deep colour if PEI was added into the dye bath for the final one hour treatment as the $2^{\text {nd }}$ step. The sum of K/S values were 110.77 and 149.27 achieved for alkali scoured wool and enzymatic scoured wool respectively after one-bath two step treatment with laccase and catechin. The area shrinkage of wool was reduced to 10.97 for enzymatic scoured and subsequent laccase treated wool after three times 5A wash cycles. This reduction of area shrinkage was due to the protease pretreatment and PEI surface absorption in the laccase treatment. When both PEI and GDE were added in the $2^{\text {nd }}$ step of the laccase treatment bath, it was found that the sum K/S value was further increased to 212.96 before washing, and the area shrinkage was significantly reduced to $6.89 \%$. It could be due to the further fixation of PEI-intergrated colorant on the wool fibre during laccase-precursor treatment. The strength of colour was increased due to the contribution from laccase-catalysed dye on both wool and PEI. Surface coating on the wool by GDE with PEI made an improvement of shrink-resistance of wool to washes.

For the laccase and gallic acid treatment bath, the same results were found. One-bath, two step treatment improved shrinkage resistance and enhanced the colour depth. Comparing between alkaline scoured and protease pretreated wool samples, it was found that protease pretreated wool fabric followed by laccase-catalysed coloration had a higher colour depth with a sum of K/S value of 102.26 and a lower felting shrinkage of $8.12 \%$. Introduction of both PEI and GDE in the later stage gave better shrink-resistance with area shrinkage of $5.68 \%$ after 3 repeat 5A washes. The sum of K/S value increased from 102.26 to 126.80 when GDE was added. The results also showed that the two-step treatment with PEI and GDE had greater effect on dyeing with laccase and catechin than that on dyeing with laccase and gallic acid. In the presence of the crosslinking agent GDE, PEI-precursor laccase-catalysed colorant in aqueous solution could be grafted onto the wool and have the potential to achieve multifunctional wool fabrics with shrink-resistance and deeper colour.

By observation of K/S values before washing and after 7A and 3 repeat $5 \mathrm{~A}$ washes, it was found that wool fabrics enzymatically dyed by laccase with precursors had reasonable good 
colour fastness to washes. Table 6 presented the images of wool fabrics dyed with laccase and catechin or gallic acid in one-bath two step process with addition of PEI and GDE. GDE did not influence the colour fastness to wash significantly. However further investigation of colour fastness of laccase-catalysed fabrics needs to be undertaken.

\subsection{SEM}

Precursors like the phenolic compounds, catechin and gallic acid, were oxidised by laccase forming polymeric colour compounds integrated with wool or PEI. The changes in surface morphology of wool fibres through enzymatic scouring and subsequent laccase-catalysation with precursors, PEI and crosslinking agent, GDE, were investigated by SEM. Fig. 11 shows that there was no noticeable damage to the cuticle cells of wool fibres after alkaline scouring process (Fig.7A). There was no obvious alteration of cuticle surface of wool but small particles formed on the fibre surface of wool due to the subsequent laccase coloration with catechin and gallic acid.

Use of protease in the scouring process might improve the efficiency in the removal of grease or lipid from wool and further partial breakdown of its cuticle scales on wool. Fig. 12 (A) shows the surface of wool fibres after protease based scouring process. Some breakdown of cuticle cells and fragments were found, but overall there was no noticeable damage of wool fibres caused by protease. This can be due to only a small quantity of protease being used in the scouring process.

Further laccase incubation with precursors in the presence of PEI and the crosslinking agent GDE might graft PEI-conjugated colour particles onto the wool fibre surface. Fig. 12 (B and C) showed the fibre surface of wool treated by one-bath two step process with laccase and gallic acid (3 hours) plus PEI and GDE for further treatment (1 hour). A rough surface with nanoscale particles was observed. These particles seem to be covered by GDE crosslinking polymers. Crosslinking film between fibres was also found on the high magnification image of wool fibre, but only in a few places.

For the catechin precursor used in one-bath two step treatment with laccase, there were a lot 
of microparticles visible on the fibre surface. These particles could be colorant polymers of catechin and PEI due to laccase catalysation and crosslinking by GDE. This could be an interesting approach through laccase catalysation for grafting particles onto wool fibre surface.

\section{Conclusions}

Wool fabrics were successfully dyed into strong muted orange and dark tan colours through laccase-catalysed oxidation of the phenolic compounds, catechin and gallic acid, respectively followed by further reaction to form their polymeric colorants. The reactive phenoxyl radicals from laccase-catalysed catechin or gallic acid could be nucleophilically attached to the amino groups of wool fibres, resulting in the formation of bonding between polymeric colorants and fibres. Therefore, there is potential for dyeing wool fibres in-situ by laccase with colourless precursors under milder conditions such as lower temperature and weaker acidity. However, laccase-catalysed coloration of wool is still in the early stage of research. Further work is required to fully understand colour formation by laccase and improve the colour property on wool.

The investigation of laccase-catalysed coloration towards either wool or the multi-primary amine compound, PEI (polyethylenimine), confirmed that amino groups from both wool and PEI are involved in the colour formation during laccase catalysation of catechin and gallic acid. The addition of PEI in the laccase-precursor system significantly affected enzymatic dyeing of wool. Colorants reacted preferably with PEI and remained in the residual laccase treatment bath, because the soluble PEI might be more accessible than wool for reaction with oxidised catechin or gallic acid radicals to form the polymeric colour compound during laccase catalysation. However, it was found that absorption of PEI on the wool fibre surface can improve wool shrink-resistance. A one-bath two step method was introduced by the addition of PEI and the crosslinking agent, GDE (glycerol diglycidyl ether), at the later stage of the laccase-catalysed dyeing process, resulting in enhanced coloration of wool and improved shrink-resistance, especially with catechin. The colour fastness to wash of wool can 
also be improved by GDE fixation. This demonstrated the potential to achieve the combined coloration and shrink-resistant finishing of wool fabrics using an enzyme-based approach and amine-contained shrink-resistant polymers.

\section{Acknowledgements}

We thank Novozymes for enzyme samples and advice on enzyme applications and gratefully acknowledge Ms Rachel Armitage and Ms Liz O'Brien for performing the scanning electron microscopy. We also thank the support from National Natural Science Foundation of China (grant number 51673087), Fundamental Research Funds for the Central Universities (grant number JUSRP51717A) and the Program for Changjiang Scholars and Innovative Research Team in University (IRT_15R26).

\section{References}

1. Shen $J$ and Smith E. Enzymatic treatments for sustainable textile processing, in: Blackburn R (Ed.), Sustainable apparel - production, processing and recycling, Woodhead Publishing Ltd, England. 2015; 119-134.

2. Claus H. Laccases: structure, reactions, distribution. Micron 2004; 35(1-2): 93-96.

3. Duran $\mathrm{N}$ and Esposito E. Potential applications of oxidative enzymes and phenoloxidase-like compounds in wastewater and soil treatment: a review. Appl Catal B: Environ 2000; 28(2); 83-99.

4. Claus H, Faber G and König H. Redox-mediated decolorization of synthetic dyes by fungal laccases. Appl Microbiol Biotechnol 2004; 59(6); 672-678.

5. Kawai S, Nakagawa $M$ and Ohashi $H$. Aromatic ring cleavage of a non-phenolic $\beta-O-4$ lignin model dimer by laccase of Trametes versicolor in the presence of 1-hydroxybenzotriazole. FEBS Lett 1999; 446(2-3): 355-358.

6. Kim S, Zillie A, Vasconcelos A and Cavaco-Paulo A. New developments of enzymatic treatments on cellulosic fibers, in: Eggleston, G., and Vercellotti, J.R. (Eds.), Industrial 
Application of Enzymes on Carbohydrate-Based Material. Washington, DC: American Chemical Society, 2007; 186-194.

7. Abadulla E, Tzanov T, Costa S, Robra KH, Cavaco-Paulo A and Gübitz GM. Decolorization and detoxification of textile dyes with a laccase from Trametes hirsute. Appl Environ Microbiol 2000; 66(8): 3357-3362.

8. Campos R, Cavaco-Paulo A and Robra KH. Indigo degradation with laccases from Polyporus sp and Sclerotium rolfsii. Text Res J 2001; 71(5): 420-424.

9. Campos R, Kandelbauer A, Robra KH, Cavaco-Paulo A and Gübitz GM. Indigo degradation with purified laccases from Trametes hirsute and Sclerotium rolfsii. J Biotechnol 2001; 89(2-3): 131-139.

10. Bourbonnais R, Leech D, Paice MG. Electrochemical analysis of the interactions of laccase mediators with lignin model compounds. Biochimica et Biophysica Acta 1998; 1379: 381-390.

11. D'Acunzo F, Galli C, Masci B. Oxidation of phenols by laccase and laccase-mediator systems. Eur. J. biochem. 2002; 269: 5330-5335

12. Aktas N, Kibarer $\mathrm{G}$ and Tanyolac A. Effects of reaction conditions on laccase-catalyzed $\alpha$-naphthol polymerization. J Chem Tech Biotechnol 2000; 75: 840-846.

13. Amic D, Davidovic-Amic D, Beslo D and Trinajstic N. Structure-radical scavenging activity relationships of flavonoids. Croatica Chemica Acta 2003; 76(1): 51-61.

14. Uyama $\mathrm{H}$ and Kobayashi S. Enzyme-catalyzed polymerization to functional polymers. $J$ of Mol Cata B Enzym 2002; 19-20: 117-127.

15. Silva C, Matamá T, Kim SY, Padrao J, et al. Antimicrobial and antioxidant linen via laccase-assisted grafting. React Funct Polym 2011; 71: 713-720.

16. Desentis-Mendoza RM, Hernandez-Sanchez H, Moreno A, Rojas del CE, Chel-Guerrero L, Tamariz J, and Jaramillo-Flores ME. Enzymatic polymerization of phenolic compounds using laccase and tyrosinase from Ustilago maydis. Biomacromolecules 2006; 7: 1845-1854.

17. Lang $G$ and Cotteret J. Composition for the oxidation dyeing of keratinous fibers containing a laccase and dyeing method using this composition. US patent 2007; $7175673 \mathrm{~B} 2$. 
18. Shin HS, Guebitz G and Cavaco-Paulo A. 'In Situ' enzymatically prepared polymers for wool coloration. Macromol Mater Eng 2001; 286: 691-694.

19. Calafell M, Diaz C, Hadzhiyska H, Gibert JM, et al., Bio-catalyzed coloration of cellulose fibers. Biocatal Biotransform 2007; 25(2-4): 336-340.

20. Hadzhiyska H, Calafell M, Gibert JM, Dagà JM and Tzanov T. Laccase-assistant dyeing of cotton. Biotechnol Lett 2006; 28: 755-759.

21. Jeon JR, Kim EJ, Murugesan K, Park HK, Kim YM, Kwon JH, Kim WG, Lee JY and Chang YS. Laccase-catalysed polymeric dye synthesis from plant-derived phenols for potential application in hair dyeing: Enzymatic colourations driven by homo- or hetero-polymer synthesis. Microbial Biotechnology 2010; 3(3), 324-335.

22. Kim S, Moldes D and Cavaco-Paulo A. Laccases for enzymatic colouration of unbleached cotton. Enzyme Microb Technol 2007; 40: 1788-1793.

23. Kim S, Lopez C, Guebitz G and Cavaco-Paulo A. (2008) Biological coloration of flax fabrics with flavonoids using laccase from Trametes hirsula. Eng Life Sci 2008; 8: 324-330.

24. Tzanov T, Silva CJ, Zille A, Oliveira J and Cavaco-Paulo A. Effect of some process parameters in enzymatic dyeing of wool. Appl Biochem Biotechnol 2003; 111(1): 1-13.

25. Bai, R., Yu, Y., Wang, Q., Yuan, J. et al., Laccase-catalyzed in-situ dyeing of wool fabric. J. Textile Inst. 2016, 107(8): 995-1003.

26. Shen J. Enzymatic treatment of wool and silk fibres. In Nierstrasz VA \& Cavaco-Paulo A (Eds.). Advances in Textile Biotechnology, Woodhead Publishing, Cambridge 2010; 171-192.

27. Nolte H, Bishop DP and Höcker H. Effects of proteolytic and lipolytic enzymes on untreated and shrink-resist treated wool. J. Textile Inst. 1996; 87, 212-226.

28. Shen J, Bishop D, Heine E and Hollfelder B. Some factors affecting the control of proteolytic enzyme reactions on wool. J. Textile Inst. 1999; 90, 404-411.

29. Smith E, Zhang Q, Farrand B, Kokol V and Shen J. The development of a bio-scouring process for raw wool using protease, Advanced Materials Research 2012; 441, 10-15. 


\section{Table legends}

Table 1. Effect of alkaline scouring and protease pretreatment on the weight loss and shrink-resistance to washing of wool fabrics and their influence on the subsequent treatment with laccase and polyethylenimine (PEI)

Table 2. The effect of catechin and PEI on laccase-catalysed coloration of wool and their felting shrinkage due to washes

Table 3. The effect of gallic acid and PEI on laccase-catalysed coloration of wool and their felting shrinkage due to washes

Table 4. CIE L* $\mathrm{a}^{*} \mathrm{~b}^{*}$ colour space values and colour strength $(\mathrm{K} / \mathrm{S})$ of wool fabrics dyed in-situ by laccase catalysation

Table 5. K/S value and shrink-resistance to wash of wool fabrics catalysed by laccase with catechin or gallic acid through one-bath two step treatment

Table 6. Images of wool fabrics dyed with laccase and catechin or gallic acid in one-bath two step process with addition of PEI and GDE 


\section{Figure legends}

Figure 1. Laccase-catalysed oxidation of substrate through mediator ${ }^{10,11}$

Figure 2. Chemical structures of gallic acid (a) and catechin (b)

Figure 3. K/S spectral data of wool fabrics enzymatically dyed with laccase in the presence of catechin and PEI

Figure 4. K/S spectral data of wool fabrics enzymatically dyed with laccase in the presence of gallic acid and PEI

Figure 5. UV-Vis spectra of the solutions containing either laccase, catechin and/or PEI after incubation at $50^{\circ} \mathrm{C}$ for 4 hours

Figure 6. UV-Vis spectra of the solutions containing either laccase, gallic acid and/or PEI after incubation at $50^{\circ} \mathrm{C}$ for 4 hours

Figure 7. Reacted solutions containing laccase, PEI or precursors in the absence of textile fabrics.

Sequence of bottles A: PEI + buffer; B: Laccase + buffer; C: PEI + laccase; D: PEI + catechin; E: Catechin + buffer; F: Laccase + catechin; G: Laccase + catechin + PEI; H: PEI + gallic acid; I: Gallic acid + buffer; J: Laccase + gallic acid; K: Laccase + gallic acid + PEI.

Figure 8. Oxidation of gallic acid by laccase into intermediate reactive quinone radicals and further polymerisation into polymeric colorants

Figure 9. Proposed chemical bonding formed between wool or PEI and the active intermediate radicals of gallic acid or its polymeric colorant catalysed by laccase

Figure 10. Schematic one-bath two step process of laccase-catalysed in-situ coloration and finishing of wool

Figure 11. SEM images of wool fibres pretreated with alkali scouring (A) and subsequently laccase-catalysed with 3\% catechin (B) or with 3\% gallic acid (C) respectively

Figure 12. SEM images of wool fibres pretreated with protease scouring (A) and subsequently processed via one-bath two step method with laccase and 3\% gallic acid (B and C) or 3\% catechin (D) respectively for 3 hours plus PEI and GDE for further 1 hour 
Table 1. Effect of alkaline scouring and protease (Esperase) pretreatment on the weight loss and shrink-resistance to washing of wool fabrics and their influence on the subsequent treatment with laccase and polyethylenimine (PEI)

\begin{tabular}{|c|c|c|c|c|c|c|}
\hline \multirow{2}{*}{ Pre-treatment } & \multirow{2}{*}{$\begin{array}{l}\text { Laccase treatment } \\
\left(\mathrm{pH} 5,50^{\circ} \mathrm{C}, 4 \mathrm{hrs}\right)\end{array}$} & \multirow{2}{*}{$\begin{array}{l}\text { Weight loss } \\
\text { (\%) due to } \\
\text { pretreatment }\end{array}$} & \multirow{2}{*}{$\begin{array}{l}\text { Weight gain }(\%) \\
\text { due to laccase } \\
\text { treatment }\end{array}$} & \multirow{2}{*}{$\begin{array}{c}\text { K/S } \\
\text { before wash }\end{array}$} & \multicolumn{2}{|c|}{$\begin{array}{c}\text { Area shrinkage } \\
(\%)\end{array}$} \\
\hline & & & & & $7 \mathrm{~A}$ & $3 \times 5 A$ \\
\hline \multirow{4}{*}{$\begin{array}{l}\text { Alkali scour } \\
\left(1.6 \mathrm{~g} / \mathrm{L} \mathrm{Na}_{2} \mathrm{CO}_{3}\right. \\
+2 \mathrm{~g} / \mathrm{L} \mathrm{UPL})\end{array}$} & Buffer & -0.71 & -1.01 & 0.59 & 1.35 & 15.85 \\
\hline & PEI + Buffer & 0.79 & -1.50 & 0.71 & 1.30 & 11.15 \\
\hline & Laccase + Buffer & -0.81 & -1.01 & 0.60 & 1.76 & 16.26 \\
\hline & Laccase + PEI & 0.60 & -0.50 & 0.61 & -0.77 & 11.93 \\
\hline \multirow{4}{*}{$\begin{array}{l}\text { Enzymatic scour } \\
(2 \mu \mathrm{L} / \mathrm{gf} \text { Esperase } \\
+2 \mathrm{~g} / \mathrm{L} \text { UPL) }\end{array}$} & Buffer & 2.67 & -0.74 & 0.50 & 1.56 & 15.41 \\
\hline & PEI + Buffer & 2.50 & -0.62 & 0.54 & 0.01 & 11.71 \\
\hline & Laccase + Buffer & 2.40 & -0.51 & 0.56 & -0.18 & 14.05 \\
\hline & Laccase + PEI & 2.30 & -0.20 & 0.57 & 0.09 & 12.12 \\
\hline
\end{tabular}

Table 2. The effect of catechin and PEI on laccase-catalysed coloration of wool and their felting shrinkage due to washes

\begin{tabular}{|c|c|c|c|c|c|c|}
\hline \multirow[t]{2}{*}{ Pretreatment } & \multirow{2}{*}{$\begin{array}{l}\text { Laccase treatment } \\
\left(\mathrm{pH} 5,50^{\circ} \mathrm{C}, 4 \mathrm{hrs}\right)\end{array}$} & \multirow{2}{*}{$\begin{array}{c}\text { Weight gain }(\%) \\
\text { due to laccase } \\
\text { treatment }\end{array}$} & \multirow[t]{2}{*}{$\mathrm{K} / \mathrm{S}$} & \multirow{2}{*}{$\begin{array}{c}\text { Sum of } \\
\text { K/S }\end{array}$} & \multicolumn{2}{|c|}{$\begin{array}{c}\text { Area shrinkage } \\
(\%)\end{array}$} \\
\hline & & & & & $7 \mathrm{~A}$ & $3 \times 5 \mathrm{~A}$ \\
\hline & $3 \%$ catechin & 0.51 & 0.90 & 18.37 & 1.23 & 16.49 \\
\hline Alkali scour & Laccase $+3 \%$ catechin & 1.43 & 11.28 & 99.32 & 1.57 & 15.16 \\
\hline$\left(1.6 \mathrm{~g} / \mathrm{L} \mathrm{Na}_{2} \mathrm{CO}_{3}\right.$ & Laccase + PEI $+1 \%$ catechin & -0.90 & 0.96 & 9.47 & 0.78 & 11.35 \\
\hline \multirow[t]{2}{*}{ + 2 g/L UPL) } & Laccase + PEI $+3 \%$ catechin & 2.26 & 2.13 & 15.44 & 1.66 & 13.67 \\
\hline & Laccase + PEI $+5 \%$ catechin & 1.21 & 3.66 & 23.64 & 0.95 & 13.96 \\
\hline
\end{tabular}


Table 3. The effect of gallic acid and PEI on laccase-catalysed coloration of wool and their felting shrinkage due to washes

\begin{tabular}{|c|c|c|c|c|c|c|}
\hline \multirow[t]{2}{*}{ Pretreatment } & \multirow{2}{*}{$\begin{array}{l}\text { Laccase treatment } \\
\left(\mathrm{pH} 5,50^{\circ} \mathrm{C}, 4 \mathrm{hrs}\right)\end{array}$} & \multirow{2}{*}{$\begin{array}{c}\text { Weight gain }(\%) \\
\text { due to laccase } \\
\text { treatment }\end{array}$} & \multirow[t]{2}{*}{$\mathrm{K} / \mathrm{S}$} & \multirow{2}{*}{$\begin{array}{c}\text { Sum of } \\
\text { K/S }\end{array}$} & \multicolumn{2}{|c|}{$\begin{array}{c}\text { Area shrinkage } \\
(\%)\end{array}$} \\
\hline & & & & & $7 \mathrm{~A}$ & $3 \times 5 \mathrm{~A}$ \\
\hline & $3 \%$ gallic acid & -0.50 & 0.92 & 8.72 & 1.62 & 15.36 \\
\hline Alkali scour & Laccase $+3 \%$ gallic acid & 1.65 & 11.73 & 130.43 & -0.34 & 14.88 \\
\hline$\left(1.6 \mathrm{~g} / \mathrm{L} \mathrm{Na} \mathrm{CO}_{3}\right.$ & Laccase + PEI $+1 \%$ gallic acid & 1.94 & 0.69 & 6.22 & 1.56 & 13.89 \\
\hline \multirow[t]{2}{*}{$+2 \mathrm{~g} / \mathrm{L}$ UPL } & Laccase + PEI $+3 \%$ gallic acid & 1.02 & 0.96 & 9.94 & 2.17 & 13.93 \\
\hline & Laccase + PEI $+5 \%$ gallic acid & 1.14 & 0.99 & 9.84 & 1.13 & 14.21 \\
\hline
\end{tabular}

Table 4. CIE $L^{*} a^{*} b^{*}$ colour space values and colour strength $(K / S)$ of wool fabrics dyed in-situ by laccase catalysation

\begin{tabular}{lcccccc}
\hline \multicolumn{1}{c}{ Pretreatment } & $\begin{array}{c}\text { Laccase treatment } \\
\left(\mathrm{pH} 5,50^{\circ} \mathrm{C}, 4 \mathrm{hrs}\right)\end{array}$ & $\mathrm{L}^{*}$ & $\mathrm{a}^{*}$ & $\mathrm{~b}^{*}$ & $\begin{array}{c}\mathrm{K} / \mathrm{S} \\
\text { at 400nm }\end{array}$ & $\begin{array}{c}\text { Picture } \\
\text { of fabric }\end{array}$ \\
\hline & Laccase $+3 \%$ catechin & 54.67 & 17.31 & 40.90 & 11.28 \\
$\begin{array}{l}\text { Alkali scour } \\
\left(1.6 \mathrm{~g} / \mathrm{L} \mathrm{Na} \mathrm{CO}_{3}\right.\end{array}$ & & & & & & \\
$+2 \mathrm{~g} / \mathrm{L} \mathrm{UPL})$ & Laccase $+3 \%$ gallic acid & 42.47 & 3.53 & 20.09 & 11.73 \\
\end{tabular}


Table 5. K/S value and shrink-resistance to wash of wool fabrics catalysed by laccase with catechin or gallic acid through one-bath two step treatment

\begin{tabular}{|c|c|c|c|c|c|c|c|c|c|}
\hline \multirow{2}{*}{ Pretreatment } & \multirow{2}{*}{$\begin{array}{l}\text { Two-step treatment } \\
\left(\mathrm{pH} 5,50^{\circ} \mathrm{C}, 4 \mathrm{hrs}\right)\end{array}$} & \multirow{2}{*}{$\begin{array}{l}\text { Weight loss } \\
(\%) \text { due to } \\
\text { pretreatment }\end{array}$} & \multirow{2}{*}{$\begin{array}{l}\text { Weight gain }(\%) \\
\text { due to laccase } \\
\text { treatment }\end{array}$} & \multicolumn{2}{|c|}{ Before washing } & \multicolumn{2}{|c|}{$\begin{array}{c}\text { Area shrinkage } \\
(\%)\end{array}$} & \multicolumn{2}{|c|}{$\begin{array}{l}\text { After } 7 \mathrm{~A} \text { and } \\
3 \times 5 \mathrm{~A} \text { washes }\end{array}$} \\
\hline & & & & $\mathrm{K} / \mathrm{S}$ & $\begin{array}{c}\text { Sum of } \\
\text { K/S }\end{array}$ & $7 \mathrm{~A}$ & $3 \times 5 A$ & $\mathrm{~K} / \mathrm{S}$ & $\begin{array}{l}\text { Sum } \\
\text { of K/S }\end{array}$ \\
\hline $\begin{array}{l}\text { Alkali } \\
\text { scour }\end{array}$ & $\begin{array}{l}\text { Laccase }+3 \% \\
\text { catechin ( } 3 \mathrm{hrs}) \text { plus } \\
\text { PEI (1h) }\end{array}$ & 0.79 & 0.79 & 11.99 & 110.77 & 1.95 & 12.27 & 8.28 & 116.82 \\
\hline $\begin{array}{l}\text { Enzymatic } \\
\text { scour }\end{array}$ & $\begin{array}{l}\text { Laccase }+3 \% \\
\text { catechin }(3 \mathrm{hrs}) \text { plus } \\
\text { PEI (1h) }\end{array}$ & 2.61 & 1.85 & 15.03 & 149.27 & 1.12 & 10.97 & 10.30 & 130.28 \\
\hline $\begin{array}{l}\text { Enzymatic } \\
\text { Scour }\end{array}$ & $\begin{array}{l}\text { Laccase }+3 \% \\
\text { catechin }(3 \mathrm{hrs}) \text { plus } \\
(\mathrm{PEI}+\mathrm{GDE})(1 \mathrm{~h})\end{array}$ & 3.74 & 2.70 & 16.60 & 212.96 & 2.49 & 6.89 & 14.31 & 194.68 \\
\hline $\begin{array}{l}\text { Alkali } \\
\text { scour }\end{array}$ & $\begin{array}{l}\text { Laccase }+3 \% \text { gallic } \\
\text { acid (3hrs) plus PEI } \\
\text { (1h) }\end{array}$ & 2.03 & 0.62 & 8.16 & 92.22 & -1.12 & 13.15 & 7.02 & 92.55 \\
\hline $\begin{array}{l}\text { Enzymatic } \\
\text { scour }\end{array}$ & $\begin{array}{l}\text { Laccase }+3 \% \text { gallic } \\
\text { acid ( } 3 \text { hrs) plus PEI } \\
\text { (1h) }\end{array}$ & 3.45 & 0.10 & 8.03 & 102.26 & 1.42 & 8.12 & 7.32 & 96.51 \\
\hline $\begin{array}{l}\text { Enzymatic } \\
\text { scour }\end{array}$ & $\begin{array}{l}\text { Laccase }+3 \% \text { gallic } \\
\text { acid }(3 \mathrm{hrs}) \text { plus } \\
(\mathrm{PEI}+\mathrm{GDE})(1 \mathrm{~h})\end{array}$ & 3.41 & 1.83 & 9.99 & 126.80 & 2.28 & 5.68 & 8.91 & 115.57 \\
\hline
\end{tabular}

Table 6. Images of wool fabrics dyed with laccase and catechin or gallic acid in one-bath two step process with addition of PEI and GDE

\begin{tabular}{|c|c|c|c|}
\hline Pretreatment & $\begin{array}{c}\text { Two step } \\
\text { Laccase treatment } \\
\left(\mathrm{pH} 5,50^{\circ} \mathrm{C}, 4 \mathrm{hrs}\right)\end{array}$ & Before wash & $\begin{array}{c}\text { After } 7 \mathrm{~A}+3 \times 5 \mathrm{~A} \\
\text { washes }\end{array}$ \\
\hline Enzymatic scour & $\begin{array}{l}\text { Laccase }+3 \% \\
\text { catechin (3hrs) plus } \\
\text { PEI (1h) }\end{array}$ & & \\
\hline Enzymatic Scour & $\begin{array}{l}\text { Laccase }+3 \% \\
\text { catechin (3hrs) plus } \\
\text { (PEI and GDE) (1h) }\end{array}$ & & \\
\hline Enzymatic scour & $\begin{array}{l}\text { Laccase }+3 \% \text { gallic } \\
\text { acid (3hrs) plus PEI } \\
(1 \mathrm{~h})\end{array}$ & & \\
\hline Enzymatic scour & $\begin{array}{l}\text { Laccase }+3 \% \text { gallic } \\
\text { acid (3hrs) plus } \\
(\mathrm{PEI} \text { and GDE) }(1 \mathrm{~h})\end{array}$ & & \\
\hline
\end{tabular}




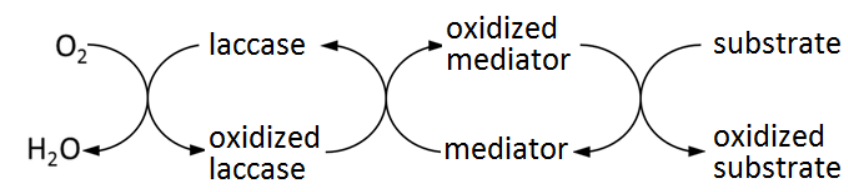

Figure 1. Laccase-catalysed oxidation of substrate through mediator ${ }^{10,11}$<smiles>O=C(O)c1cc(O)c(O)c(O)c1</smiles>

(a)<smiles>Oc1cc(O)c2c(c1)OC(c1ccc(O)c(O)c1)[C@H](O)C2</smiles>

(b)

Figure 2. Chemical structures of gallic acid (a) and catechin (b) 


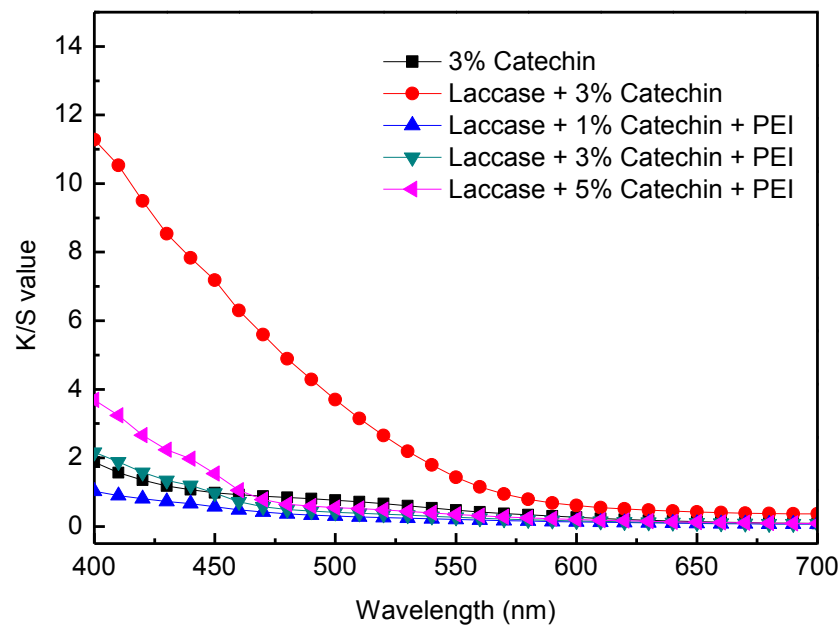

Figure 3. K/S spectral data of wool fabrics enzymatically dyed with laccase in the presence of catechin and PEI

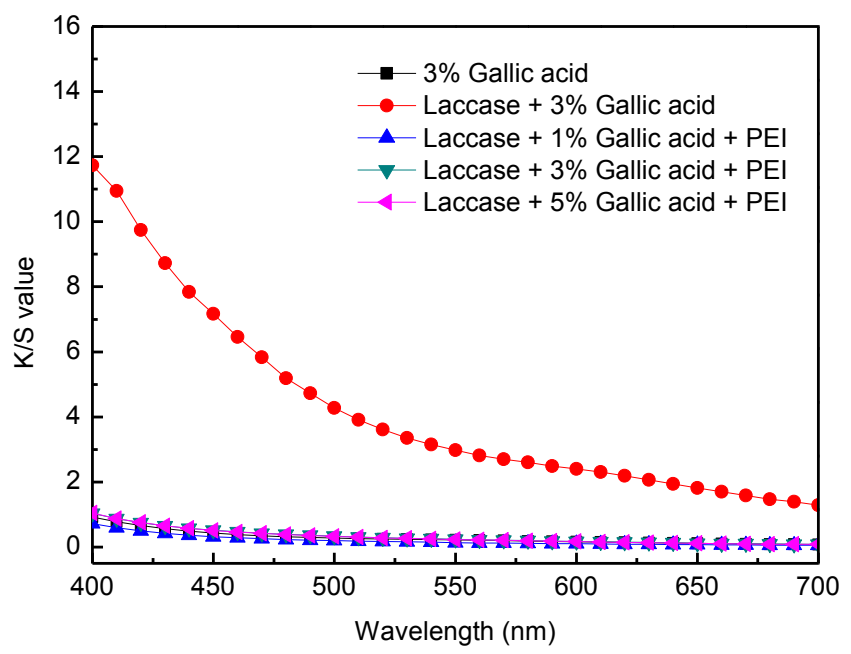

Figure 4. K/S spectral data of wool fabrics enzymatically dyed with laccase in the presence of gallic acid and PEI 


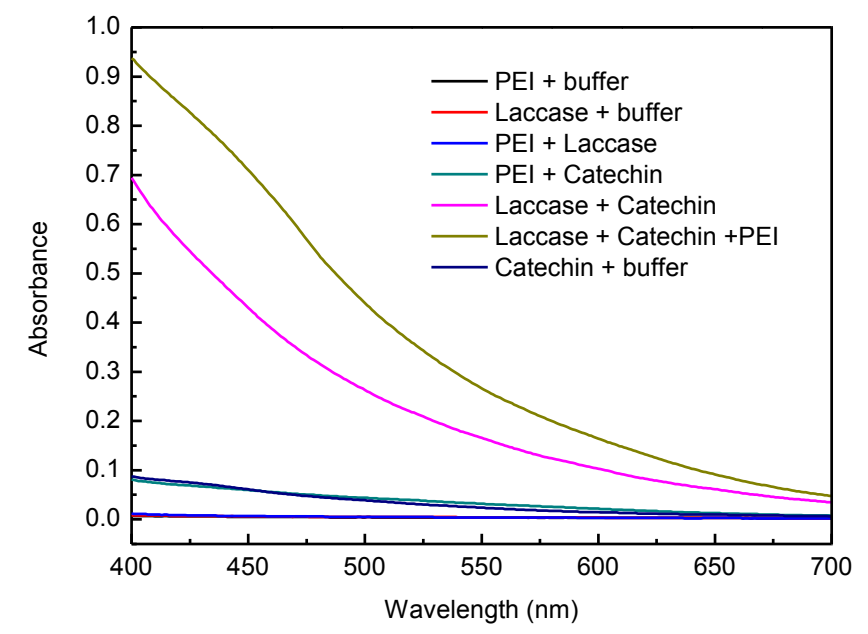

Figure 5. UV-Vis spectra of the solutions containing either laccase, catechin and/or PEI after incubation at $50^{\circ} \mathrm{C}$ for 4 hours

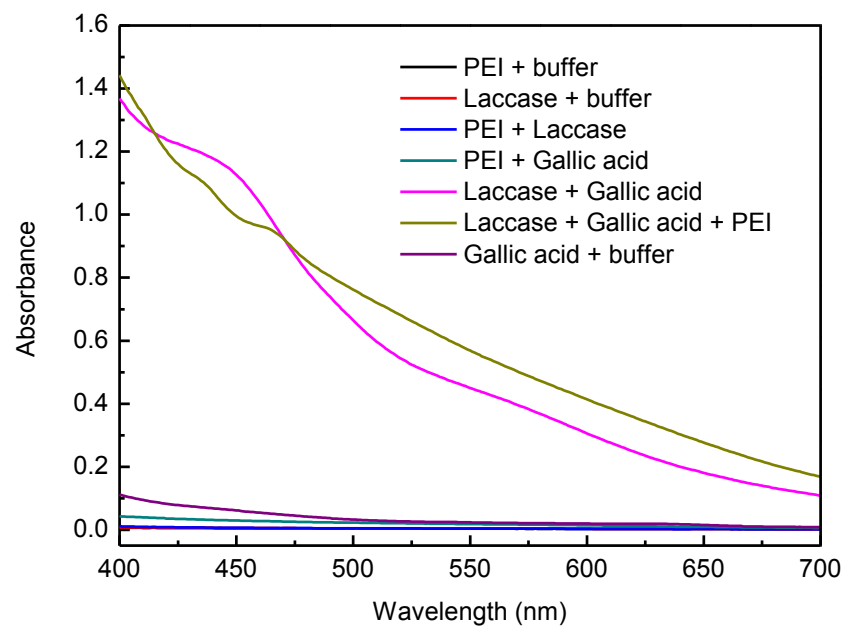

Figure 6. UV-Vis spectra of the solutions containing either laccase, gallic acid and/or PEI after incubation at $50^{\circ} \mathrm{C}$ for 4 hours 


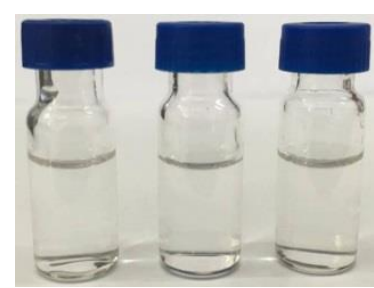

A $\quad$ B $\quad$ C

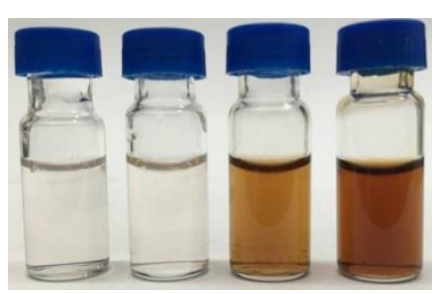

$\mathrm{D}$

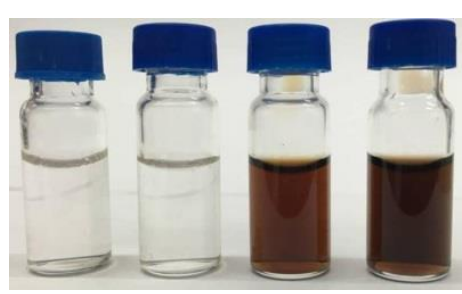

$\begin{array}{llll}\mathrm{H} & \mathrm{I} & \mathrm{J} & \mathrm{K}\end{array}$

Figure 7. Reacted solutions containing laccase, PEI or precursors in the absence of textile fabrics.

Sequence of bottles A: PEI + buffer; B: Laccase + buffer; C: PEI + laccase; D: PEI + catechin; E: Catechin + buffer; F: Laccase + catechin; G: Laccase + catechin + PEI; H: PEI + gallic acid; I: Gallic acid + buffer; J: Laccase + gallic acid; K: Laccase + gallic acid + PEI.

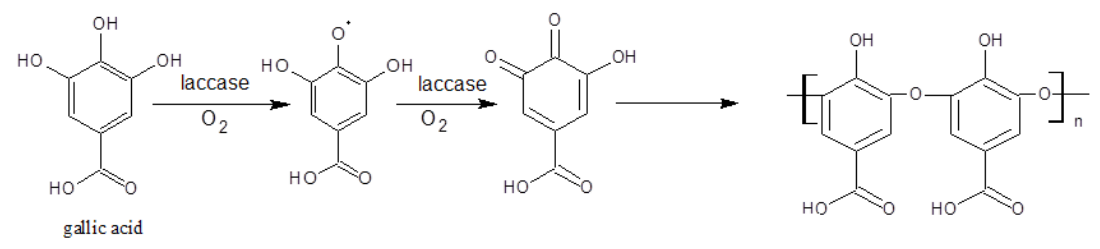

Figure 8. Oxidation of gallic acid by laccase into intermediate reactive quinone radicals and further polymerisation into polymeric colorants 


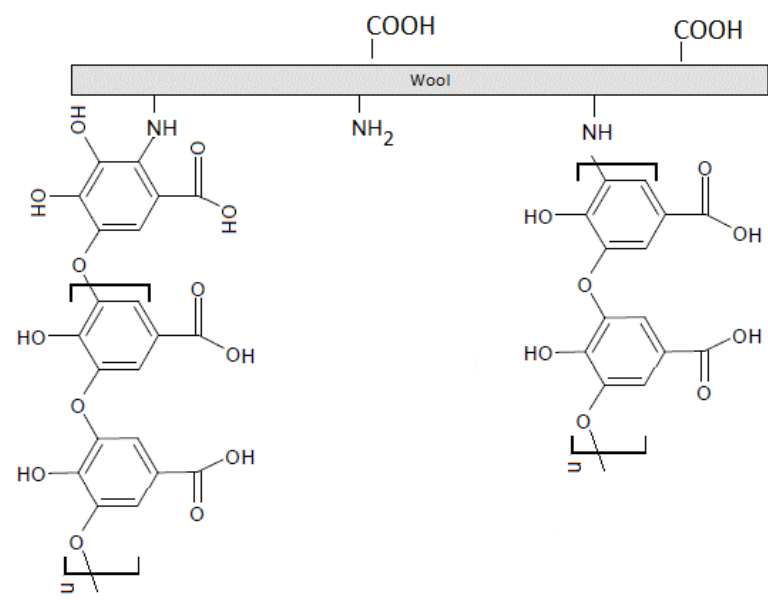

(a)

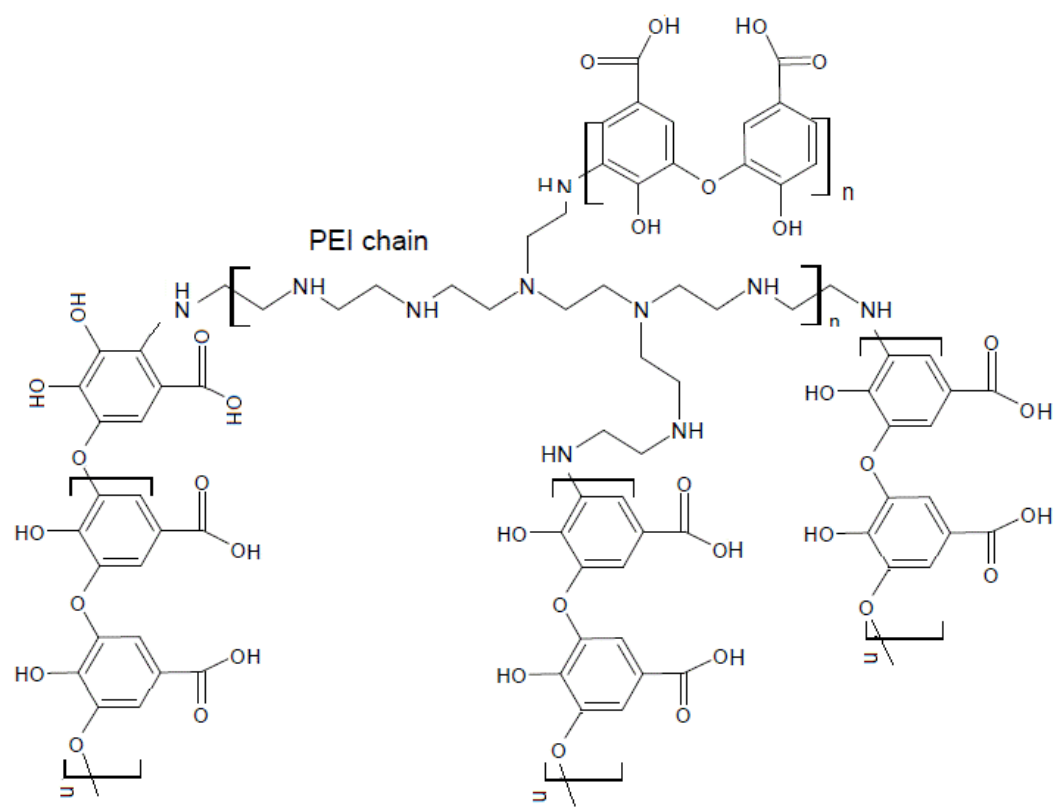

(b)

Figure 9. Proposed chemical bonding formed between wool or PEI and the active intermediate radicals of gallic acid or its polymeric colorant catalysed by laccase

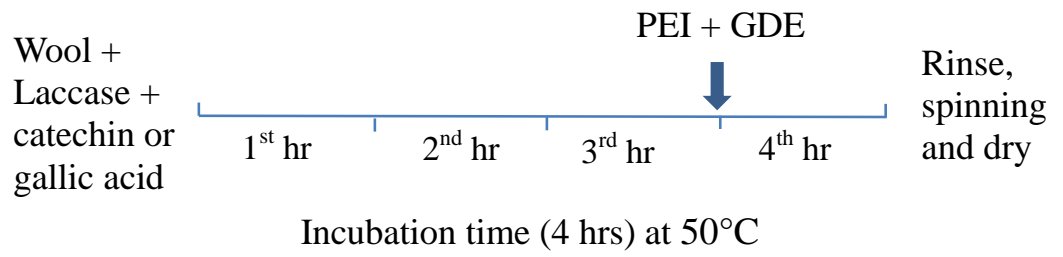

Figure 10. Schematic one-bath two step process of laccase-catalysed in-situ coloration and finishing of wool 

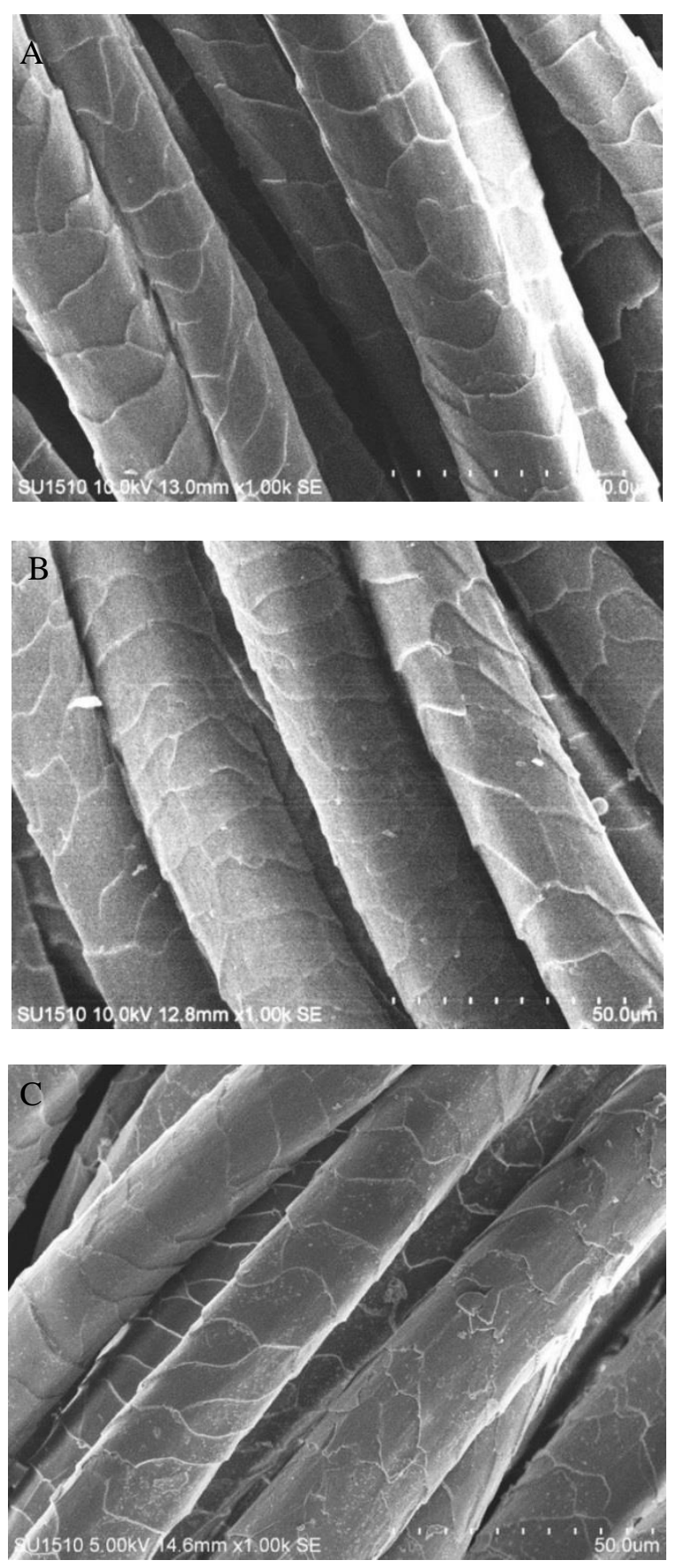

Figure 11. SEM images of wool fibres pretreated with alkali scouring (A) and subsequently laccase-catalysed with $3 \%$ catechin (B) or with $3 \%$ gallic acid (C) respectively 

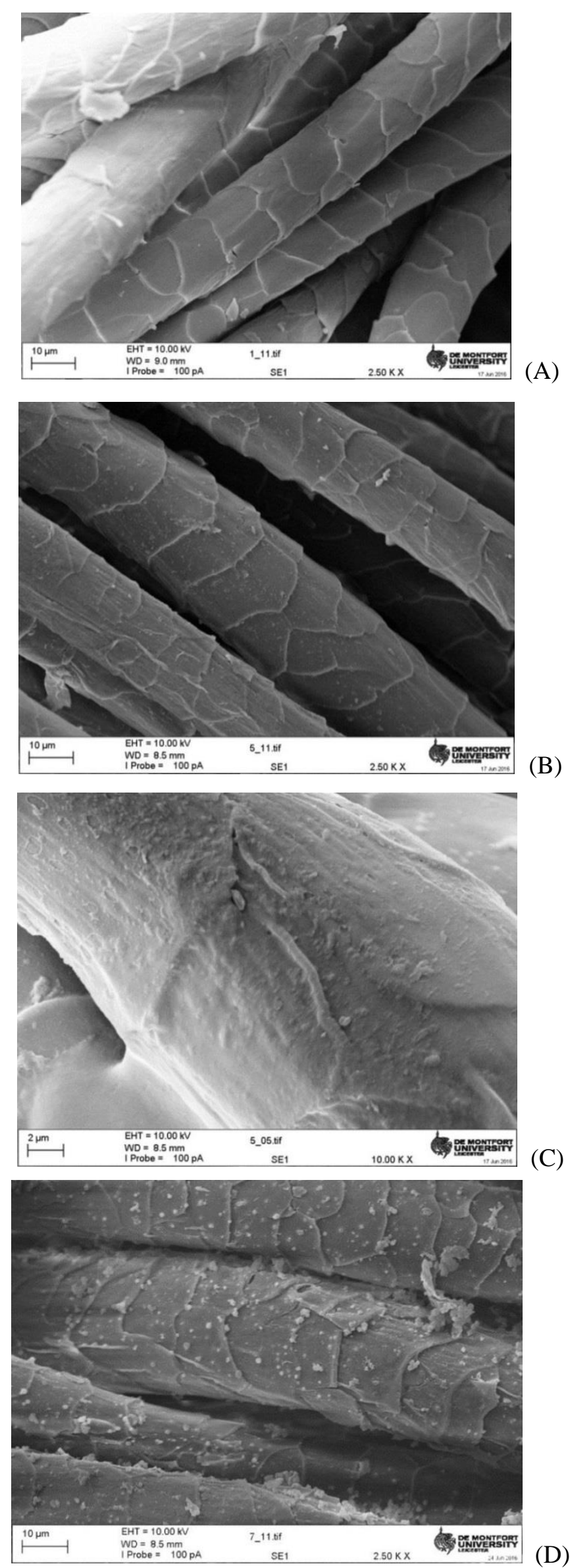
Figure 12. SEM images of wool fibres pretreated with protease scouring (A) and subsequently processed via one-bath two step method with laccase and 3\% gallic acid (B and C) or 3\% catechin (D) respectively for 3 hours plus PEI and GDE for further 1 hour 